\title{
BIOÉTICA DE LA LIBERACIÓN Y ANÁLISIS DEL DISCURSO
}

\section{BIOETHICS OF LIBERATION AND DISCOURSE ANALYSIS}

\author{
Luis Barrantes Montero ${ }^{1}$ \\ Universidad Nacional \\ luisba66@yahoo.es
}

Publicado 2016

\begin{abstract}
Resumen
El presente trabajo consiste en una reflexión con respecto a la ética en la práctica médica y en la relación del personal de la salud con el paciente y sus allegados. En especial mediante el análisis crítico del discurso, se examina el papel del lenguaje en la conformación de estructuras de poder desigual en esa relación. Con base en un relato ficticio realizado a partir de un parte médico real, y desde la perspectiva de la ética de la liberación propuesta por Enrique Dussel, con el apoyo de otros críticos de la modernidad, se busca plantear atisbos para la creación de una bioética de la liberación, en vista de que el componente deontológico debe permear todas las disciplinas.
\end{abstract}

Palabras claves: ética, bioética, ética de la liberación, análisis del discurso, medicina.

\section{Summary}

This paper consists of a reflection about ethics in medical practice as well as in the relationships between sanitary personnel and their patients and/or relatives. Especially, the role of language in conforming structures of power in those relationships are examined. Critical discourse Analysis is at the basis of the reflection. Using a fiction story, created from a real medical report, and following the perspective of Ethics of Liberation, proposed by Enrique Dussel and with the support of other critics of Modernity, first steps on the creation of a bio-ethics of liberation are offered.

Keywords: ethics, bioethics, ethics of liberation, discourse analysis, medicine.

1 El autor es académico catedrático de la Escuela de Literatura y Ciencias del Lenguaje de la Universidad Nacional, Costa Rica. Posee una especialización en la enseñanza del inglés y cuenta con grados académicos en traducción inglés-español, en teología y filosofía. En la actualidad, cursa el doctorado en Estudios Latinoamericanos de la Universidad Nacional de Costa Rica. 


\section{Introducción}

Este relato y el lacónico consejo que incluye los conocí mientras orejeaba, para entretenerme, las conversaciones de los asistentes al velorio de don Pedro, el abuelo de mi esposa, que murió en el Hospital San Juan de Dios después de muchos días de estar entubado.

\section{Mejor no dejen que la toquen}

-Ah, sí: la muerte de mamá yo no la perdono. Ayer le terminamos el novenario, pero si juera caído en otras manos, yo la juera tenido otros dítas conmigo.

-Pero, ¿qué fue lo que le cogió a doña Isabel, pa' que se agravara tan ligero? -le preguntaron.

-Bueno, vea: ella ya tenía los setenticinco, pero hace unos cinco años la habían operado de cáncer de mama y le quitaron el pecho izquierdo. De ahí jue de viajes al hospital pa' ponerle lo que llaman radioterapia. Va a hacer cosa de diez días que la doña y yo la llevamos a emergencias porque andaba como estraviada, no se daba cuenta de 'onde estaba y ni qué día era. Tenía el cuerpo como esgonzado, no se sostenía parada y no veía con el ojo derecho. Decía que le dolía la cabeza y como que le pesaba. Le hacían preguntas y algo contestaba, pero casi solo repetía lo que le decía el doctor. Y no sabía quiénes éramos nosotros, jvieran que raro!

El doctor le estuvo tocando la nuca y dijo que por dicha estaba bien (Un día de estos me di cuenta de que la nuca tiesa en esos casos es señal de un derrame). Después le hicieron exámenes de sangre y salieron normales. Por otras cosas que le hicieron en Rayos Equis me explicaron que tenía un daño en el corazón, como agrandado de un lado, y que las venas del cuerpo las tenía como aterradas y por eso costaba que le pasara la sangre y le llegara a la cabeza. Ah, bueno, también le hicieron lo que llaman "un electro" y contaba el doctor que el corazón no estaba bombeando bien, como que no le palpitaba parejo. Además, tenía la presión muy alta, cuando siempre había sido de presión baja.

Al día siguiente la juimos a ver y ya nos conoció y hasta recordaba mejor, digamos. La pasaron a un examen en una máquina que le pone como unos alambres con chupones en la cabeza y salió con un problemilla en el cerebro, pero algo poco, dijo el doctor. Y que los vasitos de las venas de la cabeza todavía aguantaban, según él. 
Pero en la tarde la pasaron a un examen groserísimo: le zamparon una aguja por la columna para sacarle un líquido que al final salió bien. ¡Pobrecita mamá, vieran los gritos que pegaba!

Empezando la noche le hicieron un "tac" y salió que le habian dado como infartos pequeños.

Ya tarde en la noche la iban a mandar pa' la casa. El doctor dijo que era un derrame porque el corazón le estaba trabajando muy forzado, que le iba a mandar pastillas pa' la presión, a ver si le emparejaban el ritmo del corazón y algo para fortalecer las venitas del cerebro. Estábamos esperando la receta cuando empezó como a faltarle el aire y a ponerse como muy colorada.

Pa' no cansalas con el cuento, la sacamos en caja. Un carajo, que también estaba esperando un cuerpo, ahí en la morgue, estudió medicina. Le conté el caso y me dijo que a una persona con derrame no se le puede meter esa aguja porque le puede subir la presión en la cabeza y se jala. ¡Eso jue! Haber sabido... Pero uno, entre lo sufrido que está y lo enredado que le hablan, iqué va a acatar a pelar el ojo!

Dice la doña que a la mamá de ustedes le está pasando algo parecido, y ya está muy mayor. Si se agrava, mejor no dejen que la toquen. Es preferible que muera queditica, siquiera sin maltrato. A uno, cuando ya lo ven muy jodido, lo cogen pa'practicar, como si el enfermo grave no juera todavía un cristiano.

Si yo juera estudiado o tuviera plata, les metería una demanda. Pero, ¿de quién se puede valer uno? ¡Qué hijueputa desgracia!

El hombre escupió en el suelo y salió a secarse las lágrimas, donde nadie lo viera.

$$
* * *
$$

El anterior relato, que sin duda tiene parangón con lo ocurrido a menudo en la realidad de muchos "cristianos" -término propio de ese narrador para referirse a las personas y evocar la indiscutible dignidad inherente a ellas-, se coloca al inicio de esta disertación porque en ella se cifra, de manera más o menos verosímil, el drama de las víctimas de abuso de los sistemas de salud, asentados en la premisa del poder médico (Solange, 2014) que les ha conferido la Modernidad. Esas víctimas “escupen” y "se secan las lágrimas” 
debido a que su alteridad, como contrapartes en el tratamiento de la salud, no pocas veces se ve disminuida, negada o anulada.

Este es un trabajo que pretende discurrir en torno al tema de las condiciones del diálogo intersubjetivo. Se pone de manifiesto que tal diálogo resulta inexistente cuando una de las partes la del personal de salud reclama de previo para sí una única condición: la de que su manera de abordar la enfermedad y su tratamiento sea incuestionable, mientras las opciones alternativas o complementarias de tratamiento ni siquiera se someten a consideración. El diálogo tampoco es auténtico cuando el papel del paciente se reduce a brindar un consentimiento informado si, en efecto y como se lee en la anterior narración, informado no lo está tanto.

La aplicación del adjetivo "informado" ante el consentimiento para una intervención médica implica, entre otras cosas, que quien lo solicita tenga clara la diferencia entre idioma y lenguaje. Según Fernández (2014), el primero se refiere a la lengua oficial de un país o nación; mientras que el segundo apunta más bien a la facultad que le permite al ser humano expresar sus pensamientos. El hecho de que un médico y su paciente "hablen el mismo idioma" no garantiza que entre ellos se dé un verdadero acto comunicativo, que le permita a este $-\mathrm{O}$ a sus allegados-dimensionar las consecuencias que se desprenden de lo que debe firmar. El lenguaje del médico, influido y entremezclado con su argot profesional, no coincide siempre y necesariamente con el del paciente, el cual termina por dar dicha autorización en medio de la premura, el temor y la confusión.

Por ello, el tema de la intersubjetividad en el uso del lenguaje se reviste de tanta relevancia. Según Díaz (2007), siguiendo a J. Habermas en su teoría de la acción comunicativa, es mediante la intersubjetividad, como re-conocimiento del otro, que la justicia, la equidad y la solidaridad humanas resultan posibles. Es la dimensión pragmática del lenguaje, o "democracia discursiva", lo que establece las condiciones reales para el diálogo del que estamos hablando.

El análisis crítico del discurso (ACD) será la herramienta fundamental para analizar aquí lo que se entiende por consentimiento informado. Lo ilustrado por la ficción referida arriba es, en principio, no un encuentro sino un choque de dos Weltanschauung, es decir, de dos cosmovisiones: por un lado, la de quien posee el poder de la ciencia médica moderna y, por otro, 
la de quien vive su cotidianidad en medio de un entramado de conocimientos y de campos de saber que, no por estar menos sistematizados que el del profesional de la salud, merezcan ser subestimados.

Una incongruencia que pondrá al descubierto el ACD en esta situación particular tiene que ver con una descuidada, mejor que alevosa, tendencia a mantener y utilizar el lenguaje "encriptado" de la disciplina científica al momento de hablar con la persona común y sus familiares o allegados acerca de la condición de esta, así como de sus posibilidades reales. Esa tendencia establece un marco de relaciones desiguales en las que la intersubjetividad es eclipsada por la posición de poder de quien se expresa con lenguaje ininteligible para el paciente y los suyos. El personaje de nuestra narración se expresa con un léxico muy coloquial y campesino. Sin embargo, ese relato ha sido compuesto a partir de un parte médico real en el que predomina un discurso del argot clínico-quirúrgico. El problema que nos ocupa, entonces, es la traslación de ese meta-lenguaje, propiedad del personal en medicina, al momento de in-formar al paciente y sus familiares para que ellos se enteren de lo que ocurre.

La ética de la liberación, desarrollada por Enrique Dussel (1998), nos ayudará a dimensionar la cuestión de manera apropiada, para que luego estemos en condición de visualizar una bio-ética de la liberación, y abrir campos de futura investigación en torno a ella. La obra de Dussel versa sobre la ética de la liberación en general, pero es tarea del personal de las distintas disciplinas, dedicado a la investigación, establecer puentes y conexiones entre la ética de la liberación y su campo específico. Es por ello que en el título de este trabajo se ha modificado el concepto de Dussel anteponiéndole el prefijo "bio", como un modesto intento de acercar ese enfoque al campo de la ética en la investigación y en la práctica médica.

\section{Después de muchos días de tenerlo entubado... Aproximaciones a la realidad del cuerpo enfermo}

En su artículo de 1998, la doctora María Luisa Pfeiffer se refiere al cuerpo humano como un "habitar" para construir intencionalmente un mundo, gracias a la capacidad de "intencionar" que posee la conciencia. Ese habitar se lleva a cabo en ambas estructuras constitutivas de la condición 
humana: la salud, en la dimensión "poder", y la enfermedad, la dimensión "no poder". En ese contexto, desde la perspectiva médica occidental, la enfermedad acontece, o sobreviene, como la falla de una determinada función o de un órgano. Es una limitación que se debe superar mediante la ayuda del médico. En dicha limitación, lo peor no está en el dolor físico sino en la restricción de la capacidad de intencionar y de significar el mundo. Al ponerse en manos del profesional en medicina, el individuo valida y refuerza el poder médico sobre todo lo que constituye su ser, no solo lo físico, sino también las emociones y lo que puede haber de espiritual en él. Esto último ha hallado explicaciones científicas en procesos neurológicos, y por eso ha quedado supeditado también a las leyes de la naturaleza, la cual es posible sojuzgar, intervenir, modificar o corregir, mediante terapias y fármacos.

Sin embargo, una manera alternativa de considerar el fenómeno de la enfermedad, según la autora, y con inspiración de cosmovisiones no occidentales, es reconocer que, si bien el ser humano es destinado al mundo, no puede abarcarlo y apropiarse de él; antes bien su vida, su paso por el mundo, es una intencionalidad un tender-al-mundo para significarlo. Eso se da tanto en la salud como en la enfermedad. Esa capacidad intencionante de nuestro cuerpo, como habitar afectivo y volitivo, es lo que nos permite temporalizar y espacializar el mundo, y también convivir con los demás.

Según la reflexión que ofrece Pfeiffer, la percepción de la enfermedad solo como un "no poder" que nos impulsa a buscar la medicina para volver al "poder" no es la única lógica posible. Existen aproximaciones alternativas al fenómeno de la enfermedad, del dolor, e incluso de la decrepitud que acontece al cuerpo con el paso de los años. Si se piensa la enfermedad de manera diferente, esta puede resultar, más bien, una oportunidad de la vida para abordar relaciones de otras maneras, oportunidad para expresar la sensibilidad y la subjetividad en formas que no se solía hacer cuando se contaba con la salud. En fin, como un modo de ser persona de una manera distinta.

Desde esa perspectiva, el abordaje de la enfermedad por parte de los profesionales de la salud se vuelve algo mucho más respetuoso: ya no procurarán intervenciones con el mero fin de solucionar una dolencia que aqueja al paciente en términos de la inmediatez, y mucho menos como ocasión para "aprender" a vencer los desafíos que la naturaleza le presenta a la ciencia. En cambio, podrán convertirse, más bien, en acompañantes que guían al 
enfermo en el conocimiento de su condición y que le recomiendan opciones complementarias para tratar su enfermedad. Eso implica aprender más acerca de las personas y de las dimensiones salud y enfermedad, que forman parte de la condición humana, pues ciertamente es más sencillo actuar desde un marco farmacológico preestablecido que desde las alternativas existentes en otras latitudes y en otras maneras de tratar el cuerpo enfermo.

\section{Pero uno, entre lo sufrido que está y lo enredado que le hablan, ¡qué va a acatar a pelar el ojo!}

La elocuente aunque sencilla sentencia de nuestro personaje introduce el tema de la desigualdad en la relación intersubjetiva personal de la salud-paciente, lo cual es objeto del ACD.

Según Wadak y Meyer (2003), no es posible conferirle un poder propio al lenguaje en cuanto tal; más bien, tal poder deriva del uso que las personas poderosas hacen de él. Por esa razón es que la lingüística crítica se decanta en preferencia por la gente que sufre antes que por el modo en el que quienes detentan el poder hacen uso del lenguaje, con lo cual se generan las desigualdades, así como de las posibilidades de que disponen para cambiar esas realidades.

Lo particular del ACD, opinan los autores, consiste en ser un discurso realizado "con actitud" (p. 144). Es, sin más, una toma de postura crítica ante la constante reproducción del abuso y la dominación ejercidos mediante el uso del lenguaje. Por tal motivo, el ACD posee, según los autores, una ética explícita en cuanto a la violación de los derechos individuales y sociales.

En el relato que abre esta disertación es evidente la disparidad existente entre el narrador, que sufre una pérdida familiar real, y el discurso y las acciones de quienes trataron médicamente a su mamá, así como el modo como le transmitieron a él lo ocurrido con la enfermedad de ella. Se nota también todo un proceso de traducción del lenguaje en dos momentos: primero, para él, por parte del personal médico y, segundo, de él para quienes atienden su relato. Pero en el primer proceso es posible advertir toda una estructura tácita de toma de decisiones, un poder establecido para intervenir a la paciente sin necesidad de advertirle a ella o sus familiares de los posibles riesgos, ni mucho menos de la finalidad auténtica de determinado procedimiento, que 
pudiera ser meramente investigativo e innecesario desde el punto de vista clínico. Por ello, Van Dijk (1999) opina que, en un acto de comunicación, los hablantes poderosos, expertos y especializados serán siempre los más influyentes. Ese criterio de autoridad resulta inapelable en la práctica para el paciente y los suyos, sobre todo cuando las circunstancias apremian. Entonces, recae mucha mayor responsabilidad ética sobre los hombros del personal de salud, pues las personas están poniendo en él toda su confianza.

Sin embargo, esa responsabilidad no siempre es honrada como sería lo óptimo. En su artículo titulado Antecedentes y fundamentos de la ética de la investigación, Brussino (2006) advierte que las prácticas habituales en el campo de la investigación tienden a ser "naturalizadas" mediante su conversión, primero en pautas y luego en normas propiamente dichas. De tal modo, la línea divisoria entre lo que los facultativos de la medicina pueden hacer y lo que éticamente deben hacer, o no hacer, suele ser tan delgada que permite fisuras que dañan los intereses de personas que confían en ellos. Y para mitigar, cubrir o solapar lo que en muchos casos son auténticos abusos, se cuenta con el recurso irrefutable del discurso profesional del galeno y otros expertos en salud.

El conocimiento de que dispone el personal de salud suele ser el criterio para que su discurso se dé por sentado como verdad. Con base en esa pretendida verdad, se redactan los documentos de consentimiento informado previos a proceder con la realización de una intervención delicada. Según Cruells (2005), el consentimiento informado consiste en un ejercicio de autodeterminación por parte del paciente, una vez que se le ha proporcionado una explicación amplia, comprensible y veraz de la situación. El problema de esos tres adjetivos que, acorde con este autor, deben cumplirse está en el grado de "verdad" contenido en cada uno de ellos y en la definición misma del concepto de verdad.

Al hacer referencia a la investigación científica, en general, pero de modo aplicable al ámbito de la medicina, en particular, el médico, biólogo y sociólogo polaco L. Fleck, (1979) sostenía que no es posible llegar a ese pretendido ideal de la verdad en la investigación científica, ya que los indagadores pertenecen y operan en el rango de determinados colectivos de pensamiento, que imprimen en ellos un estilo específico y les exigen una 
congruencia particular con él. En el mismo sentido, Vidal (2012) advierte del problema en los términos siguientes:

Sólo en Estados Unidos, por ejemplo, la industria financia casi el 60\% de la educación médica y, en particular, los llamados programas de educación médica continua para graduados. Los "trabajos fantasmas" (ghostwriting) son ejemplo de cómo la información con la que se cuenta no siempre es tan objetiva; muestra de ello han sido las reiteradas publicaciones sobre medicamentos como la sertralina, o el rofecoxibs, donde se ocultó o adecuó la información de investigaciones independientes de acuerdo con las necesidades comerciales del laboratorio, y las alarmantes publicaciones que establecen que un $11 \%$ de los artículos publicados en las seis revistas mayores de Estados Unidos serían fantasmas (p. 206).

En la práctica médica occidental, los marcos epistemológicos desde los cuales los profesionales de la medicina realizan ese ejercicio de información al paciente y sus familiares, para luego obtener de ellos el consentimiento para determinada acción, sin duda conllevan la impronta de sus respectivos colectivos de pensamiento, que bien pueden ser una escuela, una moda o una tendencia. Ya sabemos que la medicina alopática, como todo lo moderno-occidental desconoce y, en el peor de los casos, descalifica otros saberes, otras epistemes y otras posibles soluciones a los problemas reales de las personas reales.

El constructo de la verdad científica, y en particular de la verdad médica, se fortalece, sin embargo, a medida que el ser humano de hoy ha ido adoptando el lenguaje de la biomedicina para reconocerse a sí mismo (Solange, 2014). Cuanto mayor es la incorporación de ese lenguaje en la cotidianidad de la gente, señala Solange (2014), más poderoso es el discurso de la autoridad médica, pues permea con su popularidad todas las áreas de la vida humana y vuelve a los individuos más dóciles a sus diagnósticos y prescripciones. De ese modo han aparecido los conceptos de "medicalización de la sociedad" y "regulación médica del cuerpo", ambos evocan una alianza entre la política de la salud, la tecnología médico-farmacéutica y la industria sanitaria, en una clara subordinación de los individuos a procesos económicos. Por ello, la bioética va de la mano con la biopolítica. Ambas disciplinas deben realizar un análisis pormenorizado de la relación entre saber y poder 
y, sobre todo, del poder médico y el de la medicina, como generadores de políticas públicas para la explotación de los individuos, al convertirlos en blanco de explotación política y sanitaria.

\section{Pero, ¿de quién se puede valer uno?}

El narrador de nuestra historia estalla en un hondo clamor de solidaridad y justicia que luego se ahoga en la frustración infinita de una respuesta inexistente: “Qué hijueputa desgracia!” Sin embargo, la respuesta existe, pero requiere de la valentía, la determinación y la sabiduría de nuevas generaciones de profesionales, que sean formados en un talante epistemológico distinto al de la Modernidad para poder ofrecerla.

Entendemos aquí la Modernidad como una actitud y no tanto como una época. Si bien, como lo indica Ruiz (2011), la Modernidad es un modo de vida y organización social que surgió en Europa alrededor del siglo XVII, lo realmente impactante en ella es su impronta en las actitudes de las personas. Ante todo, la racionalización: una confianza exacerbada en el poder de las ciencias para resolver todos los problemas que enfrenta el ser humano. Aunado a ello, la centralidad del individuo por encima de la comunidad y el colectivo; el economicismo, como estandarización del criterio económico para valorar todas las cosas y la expansión globalizadora, que invade hasta las esferas más íntimas del ser y absorbe cualquier amago de oposición.

Esa actitud, o modo de vida, por supuesto que permeó a la ciencia médica y al cuidado de la salud en general como lo hizo con los demás campos del saber en las sociedades occidentales. El individuo común, pasmado ante el desconcierto de la ayuda que se le ofrece para atender sus dolencias, mediada por códigos de lenguaje extraños a los suyos y a los de su cultura e idiosincrasia, en el colmo de su estupor, y a veces de su indignación, saca conclusiones desafortunadas como la del título del relato de nuestra introducción.

La recomendación "mejor no dejen que la toquen" evidencia una relación que ha devenido hostil entre el médico y su paciente; o más bien, entre el médico y sus familiares. El hombre de la historia jamás supo, jamás debía saber que la punción lumbar practicada a su madre, y que produjo el desenlace fatal, tenía otra finalidad que la de ayudarle a estabilizar su salud. No se pueden subestimar los conocimientos del médico que la realizó y ponerlos 
por debajo de los del "carajo que estudió medicina". Ciertamente, debía ser conocedor de las repercusiones de ese procedimiento en las condiciones de aquella paciente, pero la oportunidad de experimentar era quizás demasiado propicia y valía la pena el riesgo. En todo caso, el discurso del parte médico sería un blindaje ante eventuales cuestionamientos.

La ética de la liberación, desarrollada por el filósofo latinoamericano Enrique Dussel (1998), ofrece abundantes derroteros para orientar ese talante epistemológico distinto que se percibe como urgente y necesario. Según este autor, la universalidad de la razón, de la vida y de la corporalidad son principios compatibles con la ética de la liberación. Esa razón es la que permite identificar la alteridad de los seres humanos dominados y su condición de víctimas. Una vez dado ese paso, es posible luego asumir una posición crítica e intentar deconstruir la validez del sistema hegemónico vigente, es decir, el sistema de pensamiento y de acción moderno-capitalista. Mediante esa deconstrucción, el conjunto de prácticas, que con el tiempo se convierten en pautas ampliamente aceptadas y de valores imperantes, es re-conocido como perverso e ilegítimo, pues es la fuente del sufrimiento de los oprimidos. Esto es lo que en otra de sus obras Dussel (1993c), inspirado en una intuición levinasiana, denomina "la irrupción del Otro" (p. 35). El Otro, el oprimido, el que habla desde la "exterioridad" del sistema económico-institucional vigente, aunque en el caso que nos ocupa sea quien sostiene con sus cuotas el funcionamiento de la seguridad social, irrumpe en demanda de justicia. Mas esta irrupción consiste en su presencia misma y en la interpelación que provoca en quien, desde adentro, desde la oficialidad, lo re-conoce y sale a su encuentro.

Podríamos preguntarnos, sin embargo, cuál es el origen de que entre los humanos existan opresores y oprimidos. En el caso de nuestra disertación, el abuso del ser humano en cuanto a su condición de enfermo y su instrumentalización para fines económicos o investigativos tiene una causa definida. Según Dussel (1998), la posibilidad de un conocimiento y un amor (pulsión) perfectos no existe. La condición humana es finita. El ser humano debe tomar decisiones en medio de la ambigüedad de esa imperfección; por ello, la posibilidad del error siempre está presente. No solo eso, sino que lo limitado del conocimiento, junto con la autoreferencialidad de los instintos de conservación, originada por el egoísmo pulsional (o falta de amor), es lo 
que sustenta el sistema vigente de opresión y dolor. Eso es el mal. Y el mal moral es la no-sensibilidad ante la victimización del oprimido.

Ese mal, afirma el autor, no necesariamente es intencional por partē de quien toma decisiones en el sistema perverso, pero se acumula a lo largo de la historia y crea estructuras de perversión que permean la institucionalidad. Por esa razón, a fin de cuentas, nadie en particular resulta responsable del mal. Solo hay un sistema viciado, que se nutre de las víctimas y se fortalece con sus colaboradores. El oprimido que "escupe en el suelo" y "se seca las lágrimas donde nadie lo vea" no puede señalar a un culpable de su aflicción. Las decisiones que ocasionaron su perjuicio están probablemente amparadas en la legalidad. En nuestro relato, el sistema como tal puede que resulte injusto, pero la culpabilidad del médico no se podrá demostrar porque no hay "plata" para demandar y sus intenciones reales permanecerán para siempre en el fuero de su conciencia.

Dussel (1998) sostiene, sin embargo, que el mal infligido a las víctimas es descubierto como una inversión de las intenciones originarias del bien, en vista del cual se habían establecido normas y se había organizado toda una institucionalidad. Al invertirse el propósito originario, el mal suscita en las personas del sistema todo un proceso de "fetichización" de su falsa verdad, y les hace percibirlo como normal y hasta correcto. Pero la crítica de las víctimas a esa no-verdad constituye la auténtica manifestación del ser humano. Por su parte, quien desde la estructura de poder del sistema, de manera responsable, logra re-conocer a las víctimas de este como sujetos autónomos en su corporalidad sufriente inicia un proceso distinto, uno de subvertir el mal. Al identificar al otro como igual, se da inicio al proceso de liberación. El acto ético consiste en ese reconocimiento. Es un deber solidario que compromete a quien estaba del lado del poder a tomar partido en favor de la víctima, lo cual, sin duda, lo convertirá en víctima sustitutiva que dará testimonio de la presencia, la existencia y la alteridad de la víctima.

\section{Conclusión}

La conclusión de este trabajo consiste en una explicación de su título o, más bien, del énfasis puesto en un prefijo que se incluye en él. Se trata del prefijo bio-, antepuesto al concepto de ética de la liberación. Este último, 
como se vio, fue desarrollado con elocuencia y amplitud por E. Dussel. Sin embargo, las múltiples derivaciones hacia las distintas disciplinas son una tarea que debe ser desarrollada a lo interno de cada una de estas.

El tema de esta disertación tuvo por objeto la ética en la práctica de la medicina, en especial en la relación entre el profesional de la salud y su paciente, o los familiares o allegados de este. Se ha señalado, de manera explícita, el papel del lenguaje como mediador entre el poder médico y las múltiples circunstancias que rodean al enfermo y los suyos.

A partir de un relato ficticio, pero inspirado en un parte médico real, de los que se realizan constantemente en los centros de salud, se ha presentado el delicado problema de la dimensión ética en la práctica de la medicina. Al hacerse referencia a la reflexión de Dussel con respecto a la ética de la liberación, se han utilizado los conceptos empleados por él para advertir acerca de la posición del paciente con respecto a la del personal de salud. Se ha dicho, entonces, que, debido a lo que se ha denominado "el poder médico", su contraparte, el paciente, queda sin poder, es decir, en el discurso de Dussel, en situación de oprimido. Esa opresión, se ha aclarado, no necesariamente es intencional; se trata más bien de una que surge de la maraña de intereses y regulaciones de un sistema institucional que opera en medio de muchas malas decisiones, producto de la limitación del conocimiento humano y del egoísmo. Esta doble fuente de error, que se ha denominado como "el mal", produce víctimas, como las del narrador de nuestro relato inicial, tanto su difunta madre como todas las demás personas que habrían sufrido esa pérdida.

Ciertamente, no se puede colegir aquí, entonces, que no hay una responsabilidad directa del personal médico por sus acciones y pretender excusarlo todo mediante la fácil explicación de que las decisiones se toman entre las prioridades de un sistema institucional imperfecto. Si bien el conocimiento humano es limitado, la voz interior de la conciencia del profesional siempre se encuentra presente para alertarle de aquellas acciones que van motivadas por el egoísmo y que son, en sí mismas, intrínsecamente malas.

En vista de lo anterior, se concluye también que la formación profesional del personal en salud debe incorporar una perspectiva inter- y transdisciplinaria, en el sentido de que no solo aborde la dimensión ética en sus planteamientos curriculares, sino que estos estén abiertos a las diferentes 
voces que aportan al respecto, sobre todo las que pertenecen a los contextos más inmediatos de cada sociedad. Existen muchos manuales de ética que han sido desarrollados desde la perspectiva europea o norteamericana, que en general sientan las bases de discusión y suelen estar a la cabeza de las bibliografías que se proponen en los planes de estudio; sin embargo, la riqueza del análisis ético desde el ángulo latinoamericano, como el que plantea Dussel, citado en este trabajo, no debería dejarse de lado. Al contrario, la reflexión ética de hoy debe atenerse a la realidad contextual de cada lugar y al marco común de los derechos humanos. Como lo plantea Brussino, citado por Vidal (2012), y en el marco de la antropología social, debe tener en cuenta "el punto de vista del actor" (p. 40). También son valiosos los aportes de la moral católica, sobre todo en el tratamiento de la formación de la conciencia moral de la persona, recinto último y definitivo en el que se toman las decisiones con discernimiento y responsabilidad.

Se dijo, finalmente, que la educación de los nuevos profesionales es el bastión mediante el cual es posible forjar la transformación epistemológica que logre un mayor interés por el componente deontológico de las profesiones, en este caso, de las que tienen que ver con la salud. Ciertamente, no se vislumbra posibilidad alguna de dicha transformación, si persiste la reticencia a escuchar las voces complementarias y si cada "proponente" emerge en un momento, pues se consume en el desfase y se pierde en el olvido. Cosa lamentable, si se tiene en consideración que las víctimas siguen clamando por una respuesta seria, duradera y responsable.

\section{Referencias}

Brussino, S. (2012). La deliberación como estrategia educativa en bioética. En Vidal, S. (Ed.), La Educación en Bioética en América Latina y el Caribe: experiencias realizadas y desafíos futuros. (p. 37-52) Montevideo: Editorial UNESCO. Recuperado de http:// www.unesco.org.uy/shs/fileadmin/shs/2012/EducacionBioeticaALC-web.pdf

Cruells, J. (2005). Conceptos de bioética y responsabilidad médica. 3. a edición. México: Editorial Manual Moderno.

Díaz, Z. (2007). J. Habermas: Lenguaje y diálogo, el rol del entendimiento intersubjetivo en la sociedad moderna. Utopía y Praxis Latinoamericana, 12, (p.47-72). Recuperado de http://www.redalyc.org/pdf/279/Resumenes/Abstract_27903904_2.pdf 
Dussel, E. (1993c). Apel, Ricoeur, Rorty y la filosofía de la liberación. México: Universidad de Guadalajara. Recuperado de http://enriquedussel.com/DVD\%20Obras\%20Enrique\%20Dussel/Textos/24/03cap2pp33-65.pdf

Dussel, E. (1998). Ética de la liberación en la verdad de la globalización y de la exclusión. México: Editorial Trotta.

Fernández, J. (Rec.). (2014). Diccionario de lingüística y ciencias afines. Hispanoteca -Lengua y cultura hispanas. Recuperado de http://hispanoteca.eu/Lexikon\%20der\%20 Linguistik/1/LENGUA\%20IDIOMA\%20DIALECTO.htm

Fleck, L. (1979). Genesis and Development of a scientific Fact. Chicago: The University of Chicago Press.

Pfeiffer, M. L. (1998). El cuerpo enfermo. Ágora: Papeles de Filosofía, 17(1), 137-149. Recuperado de http://dspace.usc.es/handle/10347/1118

Ruiz Callado, R. (2011). Modernidad, conceptos y características. Universidad de Alicante, Departamento de Sociología. Recuperado de http://rua.ua.es/dspace/bitstream/10045/16004/18/Tema\%205.\%20La\%20modernidad,\%20concepto\%20y\%20 caracter\%C3\%ADsticas.pdf

Solange, C. (2014). Biopolítica y bioética. Universidad Nacional de Córdoba, Argentina, Rede Iberoamericana de pesquisadores en História da Psicología (RIPeHP). Recuperado de http://ripehp.com/2014/10/27/biopolitica-y-bioetica/

Vidal, Susana. (2006). ¿Ética o mercado?, una decisión urgente. Lineamientos para el diseño de normas éticas en investigación biomédica en américa latina. En Keyeux, G., Penchaszadeh, V., Saada, A. (coordinadores.), Ética de la investigación en seres humanos y políticas de salud pública.191-132) Colombia: Organización de las Naciones Unidas para la Educación, la Ciencia y la Cultura, UNESCO. Recuperado de http:// unesdoc.unesco.org/images/0015/001512/151255s.pdf

Wadak, R. y Meyer, M. (2003). Métodos de análisis crítico del discurso. Barcelona: Editorial Gedisa.

Van Dijk, T. (1999). El análisis crítico del discurso. Anthropos (Barcelona), 186, 23-36. Trad. Manuel González de Ávila. Recuperado de http://www.discursos.org/oldarticles/ El\%20an\%E1lisis\%20cr\%EDtico\%20del\%20discurso.pdf 